\title{
INTERNATIONALIZATION OF ISDB-T
}

\section{Chair: Luiz Fausto - Regulatory Strategy Specialist for Globo TV Network}

After 10 years since it was adopted by Brazil as a Digital Terrestrial TV standard, the ISDB-T Japanese system has been gaining new adopters, especially in the southern hemisphere. With the exception of Colombia, Suriname and Guyanas, all other South American countries have adopted the system and, in Central America, Guatemala, Honduras, Nicaragua, Costa Rica and now, at the beginning of the year, El Salvador - have chosen the Japanese system, in the Brazilian version ISDB-TB. In Africa, it was adopted by Botswana and in Asia it was adopted by the Philippines, Sri Lanka and Maldives, as well as by Japan itself, creator of the ISDB-T standard. Today, there are about 500 million potential ISDB-T viewers. In this panel, we will have an overview of ISDB-T in the world and share the experiences and challenges faced by neighboring countries that have adopted our system.

- PRESENT STATE OF ISDB-T DEPLOYMENT IN THE WORLD Speaker: Masayuki Sugawara - Presidente DiBEG ( Digital Broadcasting Expert Group)

ISDB-T, one of the major DTTB (Digital Terrestrial Television Broadcasting) system in the world, has been adopted by 19 countries including Japan and Brazil. The state of the deployment in each country differs each other. It depends on the date of ISDB-T adoption, the analog broadcasting in the past, the future plan of the DTTB, the economic situation, etc. This lecture will survey the present state of ISDB-T deployment in each country with its background. It will also introduce the cooperative activities of the ISDB-T International Forum which was established by the ISDB-T countries.

- ARGENTINE EXPERIENCE SUMMARY Speaker: María Eugenia Muscio - Technical Advisor - CAPER

General characteristics of the television system deployed in Argentina. Progress from the adoption of the system to the date. Critical situation of the spectrum due to convergence.

- IMPLEMENTATION OF THE ISDB-T STANDARD IN THE REPUBLIC OF EL SALVADOR 


\section{Speaker: Carlos Eduardo Valle - chefe do Departamento de Monitoração do Espectro e QoS de Telecomunicações - SIGET / EI Salvador}

Describes the recent adoption of the ISDB-T standard and the steps taken towards the elaboration of a master plan and its trials that are already being performed.

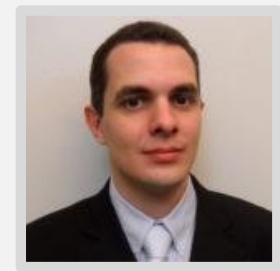

\section{Luiz Fausto - Regulatory Strategy Specialist for Globo TV Network}

Professional Master's Degree in Applied Computing (UECE - 2015), Executive MBA on IT (UFRJ - 2011), extension course in Networks and Video over IP (UFRJ - 2009), Bachelor's Degree in Electrical Engineering with emphasis in Electronics (UFRJ/USU - 2005). Currently working as Regulatory Strategy Specialist for Globo TV Network, Deputy Director of the Technology Board Committee of the Brazilian Television Engineering Society (SET), member of the Delegation of Brazil in ITU-R (SG 6) and CITEL (PCC.II), member of the TV Reception Technical Group (GT-Rx) of the Brazilian TV Switch-Over Group (GIRED), member of the Technical Module of SBTVD Forum and member of the Harmonization Working Group of ISDB-T International Forum.

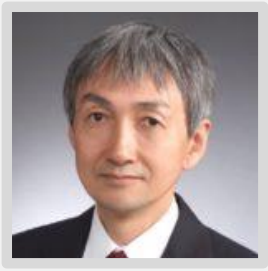

\section{Masayuki Sugawara - Presidente DiBEG ( Digital Broadcasting Expert Group)}

Masayuki Sugawara received the B.S. and M.S. degrees in electric communication engineering and a Ph.D. degree in electronic engineering from Tohoku University, Sendai, Japan. He joined NHK in 1983. He researched solid-state image sensors, HDTV cameras, and the UHDTV system at NHK STRL from 1987 to 2015 . He was an associate professor at the University of ElectroCommunications, Tokyo, Japan, from 2000 to 2004. Since 2004, he has been involved in the standardization activity at ITU-R Study Group 6 including the UHDTV standard known as Recommendation BT.2020. At present, he is the chairman of digital broadcasting experts group (DiBEG) and an executive engineer at NEC Corporation. Dr. Sugawara is a SMPTE Fellow, a Senior Member of IEEE, and a member of IEICE, and ITE.

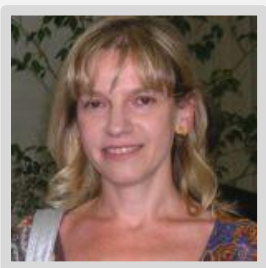

\section{María Eugenia Muscio - Technical Advisor - CAPER}

Electromechanical Engineer with Electronic Orientation graduated from the University of Belgrano. In addition, since 1990 to date, she is an Independent Consultant in Broadcasting and Telecommunications for multiple providers of television services (by subscription and open), telecommunications and radio in AM and FM, installed throughout the Republic of Argentina . He has an active performance and trajectory in Professional Institutions: Professional Council of Engineering of Telecommunications, Electronics and Computation (COPITEC) and Argentine Center of Engineers (CAI). At COPITEC, she is currently the Chief Adviser with a mandate until 2019 and Coordinator of the Broadcasting Commission since 2012. In the CAI, former Secretary of the Subcommittee on Audiovisual Communications from 2010 to 2012 and the CEYTIC Commission from 2005 to 2012. Former General Manager of Merlovisión S.A. 1992-1994. 


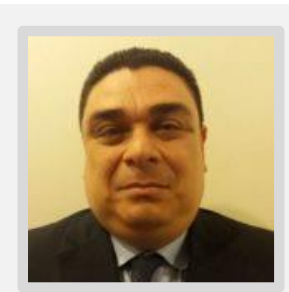

\section{Carlos Eduardo Valle - chefe do Departamento de Monitoração do Espectro e QoS de} Telecomunicações - SIGET / EI Salvador

Telecommunications Technician specialized in Transmission from the Central American Institute of Telecommunications. Industrial Engineer from the Francisco Gavidia University. Post-graduation in Telecommunication Regulation from the University of Brasilia, in Brazil. Multiple training in broadcasting technologies, $3 \mathrm{G}$ and $4 \mathrm{G}$ mobile systems and radio spectrum management and monitoring systems, inside and outside the country. Currently 16 years accumulated in SIGET (1997-2010 and 2014-2017), chief of the Department of Spectrum Monitoring and Telecom QoS, as well as technical head of the Digital Terrestrial Television and Digital Dividend project. 